\title{
Making Computer Learning Easier for Older Adults: A Community Study of Tuition Practices
}

\author{
Michael Nycyk and Margaret Redsell \\ Skylarkers 60 and Better Program, 20 Skylark Street, Brisbane, Queensland, Australia \\ info@skylarkers.net
}

\begin{abstract}
Older adults are under increasing pressure to use information technologies, yet are reluctant to learn computer software due to difficulties with ways of teaching such skills. This paper argues that examining tutoring techniques in a community computer training centre is useful to discovering why they will persist with learning. Using a Grounded Theory study design, the theory that emerged that accounted for continuance was the tutoring practices and the relationships that were built between tutor and learner. Examples from the data are presented to support the findings that link certain ways of practicing computer tutoring with repeat lesson attendance. This paper contributes to understanding the types of tutoring practices that can encourage older learners to continue the learning journey in later life. In turn, this assists with overcoming the digital divide older learners not skilled in computer use experience and allows them to participate in an increasing technologically driven society.
\end{abstract}

Keywords: computer training, older adults, digital divide.

\section{Introduction to Study}

As computer professionals our goal is to have our technologies used by society for the betterment of humankind. Education and training in computer technologies is a vital part of using them successfully. In order to be inclusive all age groups need to be considered as users and often older adults, for this paper defined as those over sixty years of age, are often excluded from computer training. In contemporary society the pressure for older adults to use the internet and computer software to find information and accomplish tasks is increasingly technologically dependent. How to encourage older adults to undertake and persist with computer education through community computer tuition practices is the subject of this paper. An answer to satisfying the computer training needs of this group lies in studying the types of community based tuition practices computer professionals teach older adults.

This paper's purpose is to demonstrate through a case study of a community centre's computer tuition programme how skilling older adults in computer software use is achieved economically and efficiently. This Grounded Theory study also describes the personal and societal benefits older people obtain from persistently learning computer software with empathic patient tutors. The discussion will be centred on why and what type of computer software tuition works for older adults. The community centre and its tuition practices will be described and the research study, its outcomes and 
implications, and what was found in terms of successful tuition for older adults, is also reported. Computer and internet training is influenced by the design quality of the training which is its major success factor [1]. Tutors are chiefly responsible for that quality. This paper will explore tuition practices and what accounts for the success of the computer tuition program at Skylarkers 60 and Better Program in Brisbane.

\section{Computer Training and Older Adult Populations}

The risk to older adults of experiencing a digital divide, that gap between individuals and opportunities to access information technologies and the internet [2], is high if they are not trained in software use. Older adults not competent in computer software and internet skills can be at a disadvantage in participating in society and the economy. There is more information being placed on the internet, more use of email and social network sites to stay in contact with others. However, the argument that tuition makes a significant difference in addressing the digital divide problem is a growing theme in computer literature.

Early studies that suggest supportive tuition works with older adults was illustrated by Danowski and Sacks [3] whose experiments with older adults concluded that older adults repeatedly use computers if a tutor was present giving individual instruction to them. Their finding suggested supporting older learners through often complex and frustrating software applications encouraged learners to continue learning the programs. In turn, older adults' negative perceptions and attitudes towards computer software learning can change towards one of seeing benefits of learning computers. Computer experiences with tutor support can change the ease of use, remove frustrations and worries, as well as reduce the perceived complexity of navigation [4].

From a technical perspective, software trainers and researchers measure computer training success through understanding, learning performance, and motivation to use, by describing attitudes towards a system or software [5]. Much research relies on statistical methods to measure such variables as performance and motivation. However, more research over time has used qualitative methods to uncover reasons for success or failure of older adult's computer training. Some reasons include the level of caution older adults have towards computers if the tasks seem too difficult or no support is offered by anyone [6]. Other researchers suggest that the software should always be relevant and interesting [7]. The theme of the usefulness and relevance of software to older occurs in much research. This is important to note because often older adults will perceive computers as being for younger people. Finally, there is a constant call for designers to design software with older audiences in mind [8].

Computer training needs to cater to the desires and wishes of the older adult learning community. For example, Kim [9] in reviewing literature on older adults and computer learning says many pitfalls that exist on the internet, such as security and identity issues, need to be taught. More research is also called for to explore the longterm outcomes of computer training to find out the nuances and complexities of why older adults will find some software useful and others not. The importance of understanding the success or not of computer software training of older adults is argued strongly by Hollis-Sawyer and Sterns who claim computer training must always meet the individual learning and motivational needs of the older person to encourage continuation of training [10]. This paper argues that the Skylarkers Computer Tuition 
Programme meets the individual needs of the student and assists in overcoming the digital divides older adults' experience.

\section{The Community Centre Research Site}

This research took place at Skylarkers 60 and Better Program, located in Inala, an outer suburb of Brisbane. The centre has a primary goal to enable older people at the local community level to participate in decisions and activities which affect their health and well-being [11]. The aim of healthy ageing at the centre is to organise and deliver activities that develop informal and forming community networks. It reflects The World Health Organisation's 1946 definition of health as 'a state of complete physical, mental and social well-being, rather than merely the absence of disease' [12].

The computer lessons began in 1996 and continue at the time of writing this paper. Most lessons are student and tutor only though the centre periodically runs a group workshop called Computers for the Absolutely Terrified. Volunteer tutors come from the community and employment training programs. They were of mixed ages, mostly male and either possessed some form of information technology qualification or had a very strong interest and practical experience in computers. Students' ages ranged from 55 to over 80 years of age. Lessons were run with adult educator Knowles [13] principles; students were to learn topics according to their past experiences and goals and importantly, the tutor had to be interested in the student's skill and personal development. Lessons were kept affordable at five dollars a session.

The computer topics taught were mostly software related, though tutors did assist with computer hardware issues. A problem solving approach was used with the tutor discussing the goals each student had before embarking on a course of study. The main software applications taught are Microsoft Word and Excel for letter writing and document production. Internet applications taught included information searching, email use and effectively using search engines. The tutors worked with students on complex software training applications such as using Photoshop to fix photographs, teaching database creation, website building and researching family histories. As research suggests, more adults want training in social networking sites, which tutors teach [14].

\section{Research Study and Design}

The study and research design was motivated by a primary observation; the centre manager observed that older adults were repeatedly attending lessons over a long period of time. Finding out the reasons for this became the centre's priority and management turned to the skills of researchers at The University of Queensland, Brisbane. The research question was what accounted for the high level of repeat computer lessons older adults learners at the centre were attending? A decision was made to design the research according to the systematic principles and methods of Strauss and Corbin's Grounded Theory methodology. This is a qualitative methodology developing theory from data by use of developing concepts and categories from interview and observational written records [15].

The primary data collection method was observations of student tutor interactions. Using Emerson et al [16] as a guide to writing field notes, the words and actions of 
each student tutor lesson were recorded. A total of 150 lessons were observed. This allowed the researchers to observe the types of interactions during the lessons and the reactions of the students to what the tutor's were telling them. To triangulate the data undertook fourteen semi-structured learner interviews. The age of the interviewees was from 65 to 76 and all attended lessons for a minimum of six months. These were used to gather more in-depth information and uncover views on the tutoring program and student experiences they had obtained from lessons. Interview questions focused on asking them to describe their experiences with computer technology and what computer problems of any kind they had solved by coming to lessons.

The analysis began soon after the observation data began being gathered. We consulted researchers and authors who had used Grounded Theory in their doctoral and research work specifically related to information technology issues of a broad scope. For example, Pace's [17] work on web interactions used Grounded Theory to analyse data by constant comparison methods in four stages: generating categories and their properties; integrating categories and their properties; delimiting the theory; and writing the theory. This is the direction the analysis took. Also used were procedures advocated by White and Weatherall [18] in their study of older adult computer users. Fieldnote and interview data was analysed using N6 qualitative computer software.

Grounded theory first uses open coding where a category is applied to the data text. The category is the abstract term that applies to the text. For example, all text on what software was used by the learner was grouped under the category of 'Software'. Each category is ascribed a property, which are the attributes of the property. For example, with 'Software" the attributes were 'use of', 'types of' and 'experiences with'; it is giving something a set of descriptors of what the observed thing is. Once these categories and properties have been assembled the axial coding takes place. This coding looks for links between the categories and groups them together [19]. Table 1 illustrates this process on how categories are arrived at from interview question, collected data and open and axial coding:

Table 1. Example of Grounded Theory Analysis Process

\begin{tabular}{|c|c|c|c|}
\hline $\begin{array}{l}\text { Interview } \\
\text { Question }\end{array}$ & $\begin{array}{c}\text { Transcript } \\
\text { Text }\end{array}$ & $\begin{array}{c}\text { Open } \\
\text { Coding }\end{array}$ & $\begin{array}{c}\text { Axial } \\
\text { Coding }\end{array}$ \\
\hline $\begin{array}{l}\text { What is } \\
\text { your opinion of } \\
\text { the tutors at } \\
\text { Skylarkers } \\
\text { overall? }\end{array}$ & $\begin{array}{l}\text { Well they're mostly pretty } \\
\text { happy-go-lucky people and } \\
\text { that puts you at ease straight } \\
\text { away. they all seem to be } \\
\text { quite with what they're doing } \\
\text { and the vibes are passed onto } \\
\text { you, when your learning, if } \\
\text { they're happy with what } \\
\text { they're doing well you } \\
\text { certainly pick up the vibes } \\
\text { that they're happy with what } \\
\text { they're doing and they're } \\
\text { happy to be there doing what } \\
\text { they do. }\end{array}$ & $\begin{array}{l}\text { Feels reassured, } \\
\text { positive experience } \\
\text { of learning, positive } \\
\text { view of tutor }\end{array}$ & $\begin{array}{l}\text { Tutor Learner } \\
\text { Relationship }\end{array}$ \\
\hline
\end{tabular}


Once the axial categories were compared the frequency of the types of categories drew out a theory from the data. The field note data and interview samples then reached theoretical saturation. When additional data does not expand categories or add any new ideas to what is occurring with the studied data. From this systematic process a theory emerged that accounted for the high student retention rate at Skylarkers computer lessons.

\section{Emerged Theory Accounting for Older Learner Continuation of Learning}

The main category that emerged from the data was the category of 'Persistence' which had a consistent property for it occurring which was described as the relationships the tutors built with the learners. What theory emerged was that older learners return to lessons because of the unique tutoring techniques the tutors at the centre employed to solve individual learner's computer issues. Certain ways of teaching software and hardware topics in a particularly caring and emphatic manner caused this to occur. Interview and field note extracts are given to support these findings. In these examples the informant's name has been changed to protect their identity.

\subsection{Evidence of Successful Computer Tuition Practice}

The older learners attending the lessons felt overall they persisted with learning basic and advanced software because of the relationship built with the tutor over time and the tutor's teaching style. Table 2 shows the relationship between the overall category 'Persistence', its property 'Tutor Relationships' and the six dimensions of the property:

Table 2. Category, Property and Dimensions

\begin{tabular}{|c|c|c|}
\hline Category & Property & Property Dimensions \\
\hline Persistence & Tutor Relationships & $\begin{array}{l}\text { Tutor being younger } \\
\text { was seen as a } \\
\text { positive influence } \\
\text { - } \begin{array}{l}\text { Duration of } \\
\text { relationship did not } \\
\text { deter participant if } \\
\text { tutor had to leave }\end{array} \\
\text { - } \begin{array}{l}\text { Tutors display high } \\
\text { amounts of patience }\end{array} \\
\text { - Tutor repeats } \\
\text { explanations until } \\
\text { participant } \\
\text { understands } \\
\text { Solving meaningful } \\
\text { problems }\end{array}$ \\
\hline
\end{tabular}


Each property dimension gives an example as to why the older learner returned repeatedly for lessons. Example one shows that the age of the tutors, often younger than the students, was a positive influence on their learning experience and encouraged them to explore how to use computer software:

I've got a microphone on my system and I talk to people in Germany, mainly Germany which is great if it's only for the fact one hears the different dialects in different parts of the country. And I was put onto that here by ... through Paltalk, you know, which gave me an insight of the possibilities and joy of it that it can bring...

Another older learner commented that during lessons the younger tutors knew how to ease older learner's anxiety:

I watch and I'm very relaxed, very relaxed. I find that they don't, none of the tutors inclined to get me excited or, I find that somebody my age, I can, they see that, they seem to know how to deal with people my age and they don't push it too far. They do it slowly for your benefit and you are, when you do get older, you are a bit slower. So you need somebody that's going to be like that with you...

An interesting dimension of the theory that kept occurring was that despite close bonds developed over time, tutors left to take up new jobs or return to study. Yet this did not deter older learners from having lessons from new tutors. The tutors that left made sure the students got acquainted with the other tutors before leaving.

The main quality an older learner computer tutor needs is high amounts of patience and willingness to repeatedly explain procedures. Each older learner valued this quality especially as they negotiated advanced features of the software they were learning as these three commented:

You say slow down do that again. So they slow down and do what they consider to be slow but its still not slow enough for a feeble mind like mine to catch up on.

You can ask the same question again and again, come back to it at the end just to make sure that you understood what they are trying to teach you.

And, no matter who it is, young or old, everyone seems to have lots of patience, is very good at explaining things. I think that's what's it all about you know.

Constantly repeating instructions can be frustrating to some computer trainers exacerbated with the pressure to deliver training quickly and on time. Yet in a community setting, there is an opportunity to repeat complex software procedures. Older learners commented that repeating an instruction was a vital part of understanding how to perform a procedure and understanding the reasoning behind the procedure:

He's very informative and makes it very simple, um, you know, I can understand what he's talking about and if I don't grasp it then he repeats it for me. He's a very good tutor. 
That is where the one to one tuition is such a big thing in my opinion. You can ask the same question again and again, come back to it at the end just to make sure that you understood what they are trying to teach you. Sometimes I walk out of here like being on cloud in a different environment altogether because of all the new things and possibilities I am shown you know.

An important dimension that accounted for persistence was that the tutors would solve computer problems the learner was having as this was important and meaningful to the learner. Two learners reported having serious learning issues with the software they were using. They both expressed the view that the tutors had worked with them to solve particularly difficult software issues, as these interview extracts illustrate, which assisted their learning to move forward:

I used to hit what I call logjams. I use the terminology logjams and I'd walk into the tutor here and say I've just had another logjam can you sort this out for me, and that meant I had problems with some of my early work of drawing up family history charts, their pretty tricky things to try and get onto a computer screen, all the lines, branches and so forth. It was a bit tricky trying to fit all that into a computer screen. That's the sort of logjams I used to have to struggle with coming here to get help with.

Yes, the other day I'm, well I'm the volunteer co-ordinator of a nursing home, and, so I have to send out various flyers. And before now I've always got somebody to do it for me at the nursing home and the other day... showed me how to do one. So I went home and I did one and sent it out and that was very pleasing.

An example from the observation data illustrated the specific interactions that reflect the tutor's systematic and patient approach was between Tom and John. The learner was elderly and had discovered that Excel would assist with his interest, share investing. However, he was continuously forgetting both how to bookmark URL's in Internet Explorer and was not aware of Boolean search engine strategies to find internet information. This exchange took place:

Tom explained the process of bookmarking favourites in Internet Explorer. Also showed John the History Page. Tom goes to the Google Search Engine and explains why it is a good page to keep.

Tom asks John to type Chemist in Google. Tom asks John to expand the window. Tom types in ASX (Australian Stock Exchange) and the page comes up (John asked if the ASX was online). Tom advises when John gets home to bookmark the page.

Tom then returns to the Chemist exercise. John types in Chemist and it results in "all the chemists in the world...that is the problem" Tom says.

Tom tells John to type in CHEMIST BRISBANE into Google. Tom says that it will reduce the number of hits (sites that come up). This happens and John clicks on one of Google's hyperlinks. Tom asks John to go back to Google and 
type in CHEMIST BRISBANE INALA. This results in an accurate search where a local chemist is found on a links site. John scrolls down looking at the hyperlinks. There is a lot of text on the site. Tom comments that in the next lesson there will be more about the ways of organising URL information in favourites.

These examples illustrate that the way tutors presented information to the learner in the manner they did does suggest that older learners felt that their individual issues were solved and a positive learning relationship was built with the tutor. The current and past tutors were all reported in some way by the learners as having these skills which encouraged them to continue lessons at the centre.

\section{Implications for Tutoring Older Adult Learners}

The main aim of this study, finding out why older learners returned to the centre for lessons, was achieved through constant observation and asking questions of the older learner about how their computer training needs were being met. It was seen after commencing the study that the tutors' teaching strategies and behaviours were influencing the decisions to return for further lessons. In this study, there was consistency of older learners reporting the tutor's had particular skills and qualities that encouraged their confidence with computer use. Emphasis should always be placed on making the first lessons a positive initial experience to reduce anxiety and build positive attitudes [20]. Centre management ensured this was a priority skill to have when choosing new tutors for the centre's computer lesson program.

The study suggests that particular tutoring practices and qualities are responsible for persistent attendance at lessons and the willingness to continue learning computers. It is argued that our study describes and defines those tutor behaviours that can contribute to building the confidence in older adult learners. It also suggests those tutoring practices that can contribute towards encouraging the older learner to continue learning computer software.

\section{References}

1. Charness, N., Schuman, C.E., Boritz, G.M.: Training Older Adults in Word Processing: Effect of Age, Training Technique, and Computer Anxiety. Int. J. Tech. and Aging. 5, 79 106 (1992)

2. Organisation for Economic Co-Operation and Development (OECD), Understanding the Digital Divide (2001), http: / /www. oecd.org/dataoecd/38/57/1888451.pdf

3. Danowski, J., Sacks, W.: Computer Communication and the Elderly. Experimental Aging Research 6(2), 125-135 (1980)

4. Adams, N., Stubbs, D., Woods, V.: Psychological Barriers to Internet usage among Older Adults in the UK. Medical Informatics \& the Internet in Medicine 30(1), 3-17 (2005)

5. Bostrom, R.P., Olfman, L., Sein, M.K.: The Importance of Learning Style in End-User Training. MIS Quarterly 14(1), 101-119 (1990)

6. Ansley, J., Erber, J.T.: Computer Interaction: Effect on Attitudes and Performance in Older Adults. Educational Gerontology 14(2), 107-119 (1988) 
7. McNeely, E.: Computer-Assisted Instruction and the Older-Adult Learner. Educational Gerontology 17(3), 229-237 (1991)

8. Seals, C.D., Clanton, K., Agarwal, R., Doswell, F., Thomas, C.M.: Lifelong Learning: Becoming Computer Savvy at a Later Age. Educational Gerontology 34(12), 1055-1069 (2008)

9. Young, K.S.: Reviewing and Critiquing Computer Learning and Usage Among Older Adults. Educational Gerontology 34(8), 709-735 (2008)

10. Hollis-Sawyer, L.A., Sterns, H.L.: A Novel Goal-Oriented Approach for Training Older Adult Computer Novices: Beyond the Effects of Individual-Difference Factors. Educational Gerontology 25(7), 661-684 (1999)

11. About Skylarkers, http://skylarkers . net/about.htm

12. World Health Organization Preamble to the Constitution of the World Health Organization as adopted by the International Health Conference, New York, June 19-22 (1946), http: / / www. who.int/about/en

13. Knowles, M.: The Adult Learner a Neglected Species, 4th edn. Gulf Publishing Company, Houston (1990)

14. Pfeil, U., Arjan, R., Zaphiris, P.: Age Differences in Online Social Networking: a Study of User Profiles and the Social Capital Divide among Teenagers and Older Users in MySpace. Computers in Human Behavior 25, 643-654 (2009)

15. Strauss, A., Corbin, J.: Basics of Qualitative Research, 2nd edn. Sage Publications, California (1998)

16. Emerson, R.M., Fretz, R.I., Shaw, L.L.: Writing Ethnographic Fieldnotes, Chicago Guides to Writing, Editing, and Publishing, 2nd edn. University of Chicago Press, Chicago (1995)

17. Pace, S.: Understanding the Flow Experiences of Web Users. PhD Thesis, The Australian National University (2003)

18. White, J., Weatherall, A.: A Grounded Theory Analysis of Older Adults and Information Technology. Educational Gerontology 26, 371-386 (2000)

19. Strauss, A., Corbin, J.: Basics of Qualitative Research, 2nd edn. Sage Publications, California (1998)

20. Mayhorn, C.B., Stronge, A.J., McLaughlin, A.C., Rogers, W.A.: Older Adults, Computer Training, and the Systems Approach: A Formula for Success. Educational Gerontology 30(3), 185-203 (2004) 